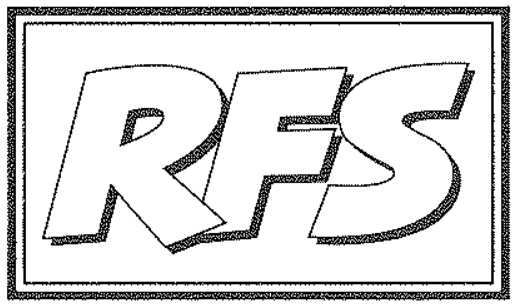

Revista de Fomento Social, 50 (1995), 3-16

\title{
Elecciones municipales en un contexto de crisis e incertidumbre
}

Consejo de Redacción

El calendario electoral español parece insaciable. No hace todavia un año fuimos convocados para elecciones europeas y, en Andalucia, también para autonómicas. En otoño pasado hubo una nueva convocatoria, aunque esta vez limitada a la comunidad autónoma vasca. Ahora están a la vista nuevas elecciones municipales y, para la mayoría de los españoles, también autonómicas. Esta acumulación casi rutinaria de convocatorias tiene, evidentemente, sus peligros. El primero de ellos es, sin duda, esa misma rutina. Pero más gravesería (jes!) que esa rutina derive en indiferencia y decepción, como consecuencia de la desconfianza que provoca el escenario político que se despliega ante nosotros.

Son esos peligros los que nos han movido a dedicar este comentario editorial a las próximas elecciones, aunque todavia nos encontramos con no pocas incógnitas por despejar al respecto. Vamos a insistir principalmente en las municipales: no sólo porque las autonómicas no se celebraran en todo el territorio nacional, sino también porque muchas de las reflexiones que siguen son 
perfectamente aplicables tanto a unas como a otras. Por otra parte, la experiencia vivida de cerca con motivo de la convocatoria andaluza del 12 de junio de 1994 nos ha hecho quizás más sensibles al peligro de que esta consulta quede una vez más desdibujada.

\section{El contexto político y el peligro de unas elecciones desvirtuadas}

En efecto, la politica española se enfrenta a una grave situación de crisis: tras sucesivos escándalos (FILESA, Banco de España, PSV, caso Roldán, $B O E$...) las cosas han llegado a extremos inconcebibles con la reanudación del caso GAL. Todo esto otorga a las próximas elecciones una especial relevancia, que desbordaría con creces el propio ámbito geográfico en que se sitúa la convocatoria. Porque se trata evidentemente de la primera ocasión en que el pueblo español podrá expresarse tras hacerse püblicos, no sólo importantes casos de corrupción, sino presuntas graves responsabilidades que involucran a altas instancias gubernamentales en un supuesto de terrorismo de estado. Es cierto que en un estado de derecho no corresponde directamente al electorado, sino a los jueces, la imputación de responsabilidades por la violación de las leyes. Pero resulta igualmente claro que la voluntad ciudadana expresada en las urnas constituye también un cauce para valorary enjuiciar la actuación de los gobernantes.

El deterioro del gobierno es tan inocultable que la oposición, tanto de derecha como de izquierda, no cesa de pedir que se adelanten las elecciones generales. Los sondeos sobre intención de voto parecen coincidir en un ascenso tal de la derecha que le permitiría alcanzar la mayoria absoluta, o al menos aproximarse mucho a ella sin olvidar el incremento del voto que se dirige a Izquierda Unida. Todo ello explica el que en estos meses de precampaña el discurso politico parezca orientarse más hacia unas elecciones generales que hacia lo que realmente vamos a celebrar.

En este sentido convendria destacar que los criterios éticos y morales pueden $y$ deben configurarse como elementos a tener en cuenta por los ciudadanos a la hora de enjuiciar la actividad politica. Bastaria recordar, a titulo ilustrativo y a pesar de la distanciay de los cambios históricos que se han producido desde entonces, la trascendental importancia histórica de las elecciones municipales de abril de 1931, que supusieron el final del régimen degradado de la monarquia de la Restauración. Más aún, la propia clase gobernante debería también 
tomar nota de los mensajes enviados por los ciudadanos, más allá del ámbito territorial de la respectiva convocatoria y de los programas que en ella se someten a debate.

Pero sería desvirtuar las próximas elecciones municipales y autonómicas el reducirlas a un mero juicio sobre la situación global en que se encuentra encerrado el gobierno. Por muy grave que sea la coyuntura, el ciudadano no puede olvidar que lo que directamente está en juego son los problemas municipales y autonómicos, que tienen suficiente consistencia en sí mismos como para centrar el debate electoral. También la clase politica tiene la responsabilidad de no eludir este debate: más aún, de ofrecer la información (programas) que el ciudadano tiene derecho a recibir antes de emitir su voto. ¿No estamos demasiado acostumbrados (ipeligrosamente acostumbrados!) a votar sin apenas prestar atención a lo que está en juego en cada convocatoria ni a las soluciones que ofrecen los partidos?

Esta seria, pues, nuestra primera propuesta, que afecta tanto a partidos y candidatos como a ciudadanos: que sepamos mantener un equilibrio, dificil sin duda, entre los dos grandes temas que se solventan en los próximos comicios. Ojalá que el apasionamiento (o la decepción) que provoca el panorama político general del pais no nos lleve a ignorar los temas más cercanos de nuestros municipios o comunidades autónomas, que son el objeto directo de unas elecciones como éstas. Pero ojalá igualmente que sepamos transmitir al gobierno (y a la oposición, por la responsabilidad que le corresponde) nuestro malestar por el deterioro dominante.

\section{La crisis económica y su marco mundial}

Tan grave contexto político no es sin embargo la única circunstancia de carácter general que rodea de un profundo malestar social a las próximas elecciones locales. A ello se une, aunque sus efectos sean diferentes, la crisis económica persistente y sus principales secuelas: las intolerables tasas de desempleo (particularmente graves en nuestra región y en Extremadura), la conciencia de que el paro se ha convertido en un factor estructural, la dureza de las medidas que se han tomado como el único antidoto contra la crisis (liberalización del mercado laboral, recortes en las prestaciones sociales...). Es indudable que comienzan a manifestarse ya sintomas inequivocos de recuperación, que el gobierno se encarga de magnificar convenientemente. 
Pero persisten otros menos prometedores, como la inestabilidad de la peseta en los mercados internacionales. En todo caso, la salida de la crisis está dejando tras de si huellas que sólo el paso del tiempo llegará a borrar. Yel hecho de que se hable de recuperación mientras se siguen padeciendo situaciones socioeconómicas que ya parecian definitivamente superadas es un factor más de crispación social.

Pero es importante discernir bien el origen y el alcance de este problema, para no mezclarlo todo en un diagnóstico simplificador. Porque los factores exógenos de la crisis, que no son los únicos, no son en modo alguno desdeñables: las grandes transformaciones en el orden mundial (tanto en el Este de Europa, como en el espacio progresivamente degradado del Sur) y el impacto creciente de las politicas europeas sobre nuestro pais, desde los primeros momentos de nuestra incorporación, configuran todo un contexto problemático que los ciudadanos debemos tener presente a la hora de emitir responsablemente nuestro voto.

El incremento de la interdependencia mundial, en un universo crecientemente informado por la revolución de las comunicaciones, genera todo un conjunto de exigencias de solidaridad como respuesta, porque los problemas de otros ya no son ajenos a nadie. Y la solidaridad tiene su primera oportunidad, su verdadero banco de prueba, en los ámbitos mas próximos donde se desarrolla la política local y regional. Esta circunstancia acrecienta el interés de las elecciones que nos ocupan.

\section{La relevancia de la esfera local}

Pero tenemos que volver a la esfera municipal $(y$, con las adaptaciones debidas, a la autonómica). Porque es a nivel local, por su mayor cercanía a los ciudadanos, donde se refleja de forma más directa el trasfondo real del malestar o bienestar de la población. De la buena o mala política municipal depende en gran medida la calidad de vida de los ciudadanos. La ordenación urbana, los servicios públicos esenciales (agua, alumbrado público, recogida de basura, transporte...), la limpieza, la seguridad en las calles, los parques y jardines, las instalaciones deportivas, etc., cosas todas que dependen de los municipios, son una parte esencial de la vida de la gente. Basta vivir de cerca la degradación urbana de ciertos barrios periféricos para convencerse de ello. Es, por consiguiente, en estos niveles donde se produce una imputación 
Las raices de este problema son múltiples. Hay ante todo una cuestión de principio: el sistema de financiación, basado mayoritariamente en transferencias procedentes del gobierno central, no sólo es insuficientesino distorsionador. En efecto, el hecho de que la búsqueda de los recursos no sea responsabilidad directa del que los gasta provoca en éste último una actitud de ligereza que tiene graves consecuencias. Asi es casi impensable el equilibrio financiero. En las actuales circunstancias, además, la cosa es aún más complicada. En efecto, desde Madrid no se ha podido hacer frente a la penuria de recursos locales, en la medida en que hubiera sido de desear, porque la crisis económica ha actuado como freno para un eventual aumento de los fondos transferidos. Por otra parte, los ayuntamientos y las diputaciones han contribuido a agravar los déficits de las haciendas locales en su afán, en si encomiable, de hacer frente a la crisis incrementando los recursos destinados a politicas sociales con la intención de amortiguar sus efectos en los sectores más vulnerables. Hay casos incluso en que se han alterado los fines de determinados programas económicos estatales para obtener recursos en los municipios que no se hubieran podido conseguir por otros caminos. Y todo ello se agrava por el modelo organizativo de los ayuntamientos, en los que tiende a sobredimensionarse el personal propio, lo que frecuentemente va acompañado de una pérdida de eficacia en la gestión.

En resumen, por razones tanto estructurales como coyunturales el replanteamiento del sistema de financiación de los diferentes niveles institucionales del Estado no admite dilación. Aunque el tema desborde por completo los objetivos de este editorial, nunca será inoportuno recordar su urgencia. Tampoco estará de más en vísperas electorales subrayar cómo en este tema están en juego no sólo aspectos técnicos de innegable complejidad, sino también una dimensión politica dificil de ocultar: porque no seria temerario sospechar que la situación de dependencia financiera de las corporaciones locales se está convirtiendo en un mecanismo idóneo para "controlar" e influir indirectamente sobre la esfera municipal, o para "castigar" la orientación mayoritaria del voto de determinados municipios. La necesidad de enfrentar y de clarificar, desde una politica de estado, las exigencias objetivas de una financiación adecuada de las corporaciones locales constituye probablemente un desafio histórico al que la propia sociedad española no debe permanecer ajena.

Ahora bien, hay otras dimensiones de la gestión de las haciendas locales que no se pueden soslayar. Y es que al político, siempre preocupado con el termómetro de las urnas, no le resulta sencillo mantener una elemental disciplina 
financiera: gastar es rentable, electoralmente hablando; la racionalidad de la decisión de gastar en función de los recursos disponibles es cuestión que alcanza menos a entender el ciudadano. Porque éste no conoce cuántos son esos recursos, mientras que es muy sensible al ritmo de los gastos y a sus efectos sobre el bienestar local. En resumidas cuentas, la tentación de endeudarse es permanente para quienes están al frente de las corporaciones locales. Y los frutos están a la vista. Pero el ciudadano tiene que terminar por preguntarse: ¿hasta qué punto es éticamente aceptable que un ayuntamiento, sea del color que sea, que tiene en principio un mandato limitado en el tiempo, esté comprometiendo hasta esos niveles los recursos de los que les sucederán en el cargo?

Dos circunstancias agravan todavia esta espinosa cuestión. En primer lugar, es frecuente que nos encontremos con razones para dudar de la oportunidad de ciertos gastos por su carácter suntuario, por mirar más al culto de la imagen de determinadas personalidades politicas que al efectivo bienestar de los ciudadanos; otras veces causa perplejidad la ligereza con que se gasta el dinero, por ejemplo, en campañas pseudo-culturales o en subvenciones a gruposy asociaciones "fantasma" (de las que apenas se sabe sino que son destinatarios de fondos públicos). En segundo lugar, tampoco el ámbito local está exento de la sospecha de corrupción, que parece alcanzar a todos los niveles de la administración pública. No queremos hacer con esto una denuncia generalizada e indiscriminada, porque seguimos convencidos de que son muchos los que desempeñan sus cargos políticos con toda honestidady por eso precisamente no salen del anonimato. Pero los casos que han saltado a la palestra pública sirven para ponernos en guardia de otra posible fuente de problemas en el control de las haciendas municipales (y autonómicas).

\section{La gestión política municipal}

Pero en último término los recursos económicos, que han ocupado nuestra atención en el apartado anterior, tienen un carácter meramente instrumental. Están al servicio de la satisfacción efectiva de las necesidades concretas de los ciudadanos. Es aqui, por tanto, donde ha de centrarse el juicio político de los electores: en la valoración de la gestión realizada por los que actualmente ocupan el poder, asi como de las posibilidades alternativas presentadas por los grupos en la oposición. Será entonces la condición de "vecino" de un determinado municipio la que tendría que determinar en última instancia la perspec- 
tiva (necesariamente "crítica") desde la que se conformará la opinión ciudadana llamada a expresarse en las urnas. Y esa perspectiva valorativa deberá descender a temas muy concretos y particularizados; habrá que analizar la capacidad de respuesta que hayan demostrado los gestores de los ayuntamientos ante las demandas particulares manifestadas en cada pueblo, en cada aldea, en cada municipio. En contraste con la uniformidady la generalidad de las respuestas que suelen formular los partidos, a veces a través de simples eslóganes, los problemas y las necesidades de ámbito local se caracterizan por suenorme diversificación. Como ciudadanos hemos de exigir a los partidos que no rehuyan este terreno donde se les va a pedir la máxima concreción, y que eviten, en cambio, las estrategias electoralistas de carácter generalizador o "ideológico" que enmascaran las singularidades territoriales y los factores singulares, inherentes al ámbito micropolitico propio de la esfera local.

En momentos de crisis de las grandes construcciones ideológicas y de un sano escepticismo ante las fórmulas universalistas o globalizadoras para la resolución de los problemas ciudadanos, la esfera singulary personalizada de la democracia municipal puede constituir un interesante banco de pruebas en el que valorar la capacidad efectiva de gestión y de resolución de problemas sociales a los que en última instancia debe responder la esfera politica. La democracia construida "desde abajo" tendria justamente en la esfera local su mejor horizonte de referencia, en unos ayuntamientos que deberán encargarse de gestionar los problemas ciudadanos hasta el mismo umbral del siglo XXI.

\section{Elecciones municipales y clientelismo político}

El carácter local de las próximas elecciones suscita una nueva cuestión, derivada de las peculiaridades de los procesos politicos que se vienen desarrollando en la Europa del Sur, dentro siempre de un esquema básicamente democrático. La dualidad entre medio ruraly urbano sigue constituyendo uno de los problemas pendientes dentro del proyecto de vertebración de nuestra tierra. No es raro que bajo la presión de la penuria socioeconómica y con la connivencia de un cierto atraso cultural se busque una oportunidad de mejora al amparo de la dinámica electoral. Y sabemos que los políticos se prestan con más frecuencia de la deseada a entrar en el juego del clientelismo. De esta forma es fácil que, en áreas rurales especialmente atrasadas de nuestra geografia yobjetivamentenecesitadas de una amplia laborde asistencia social, los recep- 
tores de ayudas públicas se sientan obligados a responder mediante una contraprestación en forma de voto a un determinado partido; y los politicos locales, por su parte, no rehusan explotar esta necesidad real como una oportunidad para incrementar su numero de votos. Estariamos entonces reproduciendo esas pautas clientelares que tanto han contribuido a desacreditar y arruinar la auténtica democracia. $Y$ es que tal fenómeno constituiría un grave atentado contra las exigencias de libertad politica que deben presidir el comportamiento ciudadano en toda democracia. Por estas razones queremos hacer un llamamiento al comportamiento responsable, libre y crítico, tanto de los electores como de los propios candidatos y sus esferas institucionales de influencia; pues la verdadera libertad no se conquista solamente ni con las grandes declaraciones legales o constitucionales, ni mucho menos con prácticas clientelares abiertas o disimuladas, sino con el ejercicio efectivo del libre albedrio en el comportamiento politico cotidiano.

Pero el fenómeno no es exclusivo del mundo mural. Podría igualmente reproducirse en áreas urbanas periféricas, o en el seno de determinados grupos sociales dependientes (pensionistas...), susceptibles de sentirse "amenazados" ante un cambio de mayoría que pudiera interpretarse como un riesgo para la percepción de sus subsidios o ayudas sociales. En este caso sería la variable "edad" la que condicionaria el voto: porque hoy no son los jóvenes (a pesar de que son ellos los más afectados por el paro y la falta de perspectivas de futuro) los que más votan a los socialistas, sino los mayores (las clases subsidiadas, satisfechas con su situación y temerosas de perderla). Otra variable a considerar como factor condicionante del voto es la situación laboral: y no pensamos tanto en los parados como en el colectivo numeroso de empleados de las distintas administraciones por designación, que también mantienen su fidelidad de voto por razones a todas luces interesadas. Dentro de la casuistica cuasi infinita que genera la vida local de los pueblos y de las ciudades y sus barrios, no es infrecuente captar cómo estas necesidades tan perentorias para determinados sectores son utilizados con fines electoralistas por miembros tanto del partido del gobierno como de la oposición. En ningún caso semejante tipo de actitudes o de temores debe aceptarse como una pauta auténticamente libre y democrática de comportamiento, puesto que limita y condiciona el ejercicio de la genuina libertad de opciones por parte de los electores. Pero más grave es la responsabilidad de los que se valen de ello sin otra intención que la compra del voto. 


\section{Las ofertas politicas previsibles}

Es pronto para analizar las posibles ofertas de los distintos partidos, sobre todo cuando la atención politica está tan desplazada hacia otros horizontes. Con todo, cabe adelantar ya algunas reflexiones.

En la preparación de las distintas candidaturas, parece que en principio las diferentes fuerzas politicas se enfrentan a los comicios con el propósito de renovar notablemente sus listas. Por parte del Partido Popular, parece que mantiene su estrategia de desplazamiento hacia el centro, aunque sigue más volcado en la tarea de acoso al gobierno que en la de elaborar una verdadera alternativa. En todo caso habrá que comprobar si la tendencia alcista de las últimas convocatorias, $y$ de los recientes sondeos, persiste o más bien está alcanzando ya su "techo" electoral. No parece, en cambio, percibirse por ahora una estrategia paralela de moderación por parte de Izquierda Unida, aunque según todos los sintomas continúa detrayendo electorado de izquierda al PSOE. También en el PSOE se advierte un intento de renovación en las candidaturas, que se enmarca en el contexto de conflicto entre renovadores $y$ guerristas; era previsible, sin embargo, que el deterioro del gobierno tras las últimas elecciones y los escándalos posteriores hubiere impulsado a ambos sectores a cerrar filas como último recurso para salvar la situación. En Andalucia, por fin, siguen constituyendo una incógnita las perspectivas de recuperación del electorado andalucista, entre otras razones como consecuencia de la división de su oferta.

También es arriesgado hacer predicciones sobre cuáles podrian ser los resultados. En todo caso, no es una cuestión decisiva para el elector. Los resultados deberian ser ante todo la consecuencia de decisiones libres de los ciudadanos, sin estar sometidos a esa bombardeo abrumador de encuestas y sondeos preelectorales, muy diferentes en cuanto a su valor técnico y casi siempre de sospechosa intencionalidad. En este sentido, quizás seria deseable que los cuantiosos recursos destinados a esos innumerables sondeos previos se reasignaran para reforzar la seriedad de la campaña y dar ocasión a los candidatos para presentarse ante los ciudadanos con propuestas concretas y susceptibles de debate.

Pero algo se puede aventurar sobre posibles resultados. De mantenerse las tendencias constatadas en los últimos meses y en las más recientes convocatorias, cabe esperar un ascenso de Izquierda Unida y del Partido Popular sobre 
los resultados obtenidos en las anteriores elecciones municipales, paralelo al predecible descenso del PSOE tras la grave crisis de gobierno a la que se viene enfrentando. Más allá de sus efectos inmediatos sobre la constitución de ayuntamientos y diputaciones, el alcance de estas variaciones será determinante para la estabilidad del gobierno central; cuanto más considerable sea el ascenso del Partido Popular, mayores serán las probabilidades de una crisis de gobierno, sin excluir la convocatoria no lejana de elecciones generales; pero si los resultados favorecen a los socialistas más de lo que parecen predecir los sondeos, como ha ocurrido en otras ocasiones, entonces será el gobierno quien saldrá reforzado. Como ya hemos indicado más arriba, esta previsible repercusión de las elecciones locales sobre la situación política general va a condicionar más de lo deseable la campaña electoral, como ya está afectando a la precampaña misma.

Por eso reiteramos nuestra llamada a no perder de vista por parte de nadie, ni políticos ni ciudadanos, lo que directamente está en juego en las elecciones municipales y autonómicas. Su efecto más inmediato podría ser que no pocos ayuntamientos cambiasen de manos $o$, al menos, quedasen sin una mayoria suficiente. Probablemente esto dependerá en gran medida de la capacidad de las dos fuerzas politicas en alza para aproximarse al electorado "de centro", porque ése es, en última instancia, el verdadero soporte de las mayorías reiteradamente conseguidas por el partido en el gobierno durante la última década. Pero también será decisiva la actitud del electorado: la gran incógnita es si mantendrá esa cierta fidelidad de voto que le ha venido caracterizando (lo que está en la raiz de muchos errores de los sondeos preelectorales) u optará por un comportamiento más elástico rompiendo con la tendencia dominante desde la década de los ochenta.

Esta cuestión conecta con la de la alternativa bipartidismo-multipartidismo, uno de los eternos temas polémicos de la ciencia política. En principio, una tendencia bipartidista es, a largo plazo, perjudicial porque acentúa la conflictividad del sistema social, lo que resultaría especialmente grave en un contexto tan degradado como el nuestro. Sin embargo, fuerza es reconocerque, en pura teoría, el bipartidismo es el modelo más simplificado posible. En cambio, los sistemas de partidos en los que alguienocupa el "centro" provocan efectos de moderación que mejoran la gobernabilidad; pero, llevado a su extremo, podria degenerar en ingobernabilidad por la dispersión de las fuerzas políticas. En todo caso, es un tema de debate y polémica. 


\section{Las posibilidades de coalición}

La hipótesis de que en la convocatoria de la próxima primavera salga reforzado el pluralismo merece también algún comentario. Habrá que contar no sólo con los tres partidos de mayor implantación estatal, sino también con los partidos nacionalistas y regionalistas. La consecuencia más destacable de un mapa poselectoral pluralista será la necesidad de intentar pactos de gobernabilidad. Porque es dificil imaginar que, en las condiciones actuales de virulencia en las relaciones entre los partidos, se vaya a llegar a coaliciones preelectorales (¿lo conseguirán siquiera en Andalucía los dos partidos regionalistas, Partido Andalucista y Partido Andalucista de Progreso?). Hay indicios para pensar que el PSOE se inclina por ahora a repetir la experiencia de 1979, mediante una coalición de izquierda con IU; pero habrá que ver si esta expectativa se confirma, porque igualmente cabe la posibilidad de que los partidos mayoritarios de la oposición prefieran acentuar su presión sobre el gobierno, para forzar la convocatoria de elecciones anticipadas. No podemos silenciar que esta estrategia nos inquieta, si tras ella sólo se oculta como objetivo el provocar la caída del gobierno: ¿sería éticamente aceptable que todo lo que está en juego en unas elecciones municipales y autonómicas quedara subordinado a un objetivo de orden tan diferente? ¿no equivaldria dicha estrategia a una absolutización de la conquista del poder sin reparar en los medios?

La reciente experiencia del gobierno andaluz que salió de las urnas en junio del pasado año, totalmente bloqueado por la imposibilidad de llegar a una mayoria a través de pactos, parece aconsejar que no se ahorren esfuerzos para alcanzar unos niveles minimos de gobernabilidad. En la medida en que ningún partido consiga en muchos municipios una mayoria suficiente para gobernar, la fuerza de los hechos tenderá a imponer sus dictados.

El asunto de los pactos es delicado, no sólo por las malas disposiciones actuales de los partidos a entenderse entre ellos, sino también por las reacciones frecuentemente airadas de los electores ante estas alianzas poselectorales. $Y$ sin embargo no se puede cerrar los ojos ante las exigencias del pluripartidismo, en el caso de que, por capricho de las matemáticas electorales, nadie estuviera estrictamente legitimado para gobernar y llevar adelante su programa completo. Pactar significa llegar a un acuerdo en cuanto a los programas, y esto implica que las partes se sienten a negociar y acepten renunciar a algunos aspectos de sus posiciones. Si dichos pactos no son 
posibles a priori, o los partidos no los consideran convenientes, habrá que negociarlos después. El elector no debe excluir esta hipótesis, aunque sí tiene derecho a exigir que las negociaciones sean transparentes.

\section{A modo de conclusión}

Es fácil que las próximas elecciones no despierten en la sociedad española un excesivo entusiasmo. Al desinterés que venía incubándose entre nosotros una vez pasada la efervescencia de la transición, se une hoy la decepción ante lo que ha dado de si la democracia tantos años esperada.

Con las páginas que preceden hemos querido poner de relieve lo que está en juego en las elecciones que se aproximan. Creemos que lo vivido en las últimas convocatorias invita a distinguir un doble nivel: de una parte, el juzgar de la gestión de ayuntamientos y diputaciones y el pronunciarnos sobre las iniciativas que ahora se proponen; pero también el hacer llegar al gobierno y a los partidos en general el malestar ante el panorama politico que nos circunda y ante las vias por las que poder constituido yoposición le están haciendo frente. Quedarse sólo en lo segundo seria desvirtuar el sentido particular de estas elecciones; prescindir por completo de ello seria caer en una total irresponsabilidad politica.

La mayor irresponsabilidad de los ciudadanos seria, desde luego, encogerse de hombros ante lo que está ocurriendo y desentenderse de la vida politica. La opinión de algún prestigioso intelectual aconsejando que no se vote para advertir a los politicos sobre el desacuerdo con el sistema, aunque respetable, nos parece poco coherente con los principios democráticos. Y son los partidos politicos los primeros que han de salir al paso de esta tendencia cada vez más generalizada. La próxima campaña es una oportunidad a no desaprovechar para convenceralelectorado de que, más que en ellos mismos y en sus intereses de partido, piensan en el bien de la sociedad, que no subordinan los intereses legitimos de ésta a las conveniencias de las estrategias electorales. No será tarea fácil. Tendrian que comenzar por renunciar a inercias tan arraigadas en ellos como son la descalificación por la descalificación, el refugiarse siempre en los discursos grandilocuentes y en las grandes afirmaciones incontrastables, el no rehuir el debate de lo concreto... Unas elecciones municipales, precisamente por su mayor cercanía a los problemas del ciudadano, ofrecen una inmejorable ocasión para ello. 
Decisivo será, por fin, el papel de los medios de comunicación social. Recientemente han venido prestando un inapreciable servicio a la sociedad. Algunos deseariamos, sin embargo, ver una mayor transparencia en sus intenciones, reflejada, por ejemplo, en el modo y el momento en que se dan ciertas noticias... No se trata de poner en cuestión la libertad de expresión, uno de los pilares de toda democracia, y mas todavia cuando las instituciones públicas son tan opacas como las españolas. Pero el ejercicio de esta libertad en nuestro país debe ser también enjuiciado bajo el prisma del sesgo que se esta imprimiendo al conocimiento de una realidad de la que sabemos lo que los medios quieren, como y cuando lo quieren. La libertad de expresión siempre tendrá como límite el derecho del ciudadano a ser informado y a no ser manipulado. Pero en la sociedad española existe una impresión bastante generalizada de que la información nos llega filtraday dosificada, sin que casi nunca lleguemos a saber en función de qué criterios o intereses.

¿Seguirá siendo esa la tónica de los medios con ocasión de las próximas elecciones? ¿Serán capaces, por esta vez, de contribuir a no enrarecer más el clima politico? ¿Darán opción a los candidatos para exponer sus programas cumpliendo con el deber de informar a los ciudadanos? ¿Les exigirán, en nombre de toda la sociedad, propuestas concretas y susceptibles de debate? ¿Eludirán la tentación de reducir las elecciones a una ocasión más para aumentar sus tiradas (o su audiencia) y llenar sus páginas (o sus espacios publicitarios) con insipidos mensajes electorales?

Si la democracia española está en crisis, ¿no es tarea de todos contribuir a sacarla de ella? ¿Y cómo mejor que aceptando seria y responsablemente sus reglas del juego cuando somos una vez más llamados a las urnas? 